\title{
Study on Underwater Optical Communication System for Video Transmission
}

\author{
Hyun-Joong Son", Jin-Il Kang ${ }^{* *}$, Thieu Quang Minh Nhat", Seo Kang Kim and Hyeung-Sik Choi®* \\ "Division of Mechanical and Energy Systems Engineering, Korea Maritime University, Busan, Korea \\ BORsys Co. Ltd., Busan, Korea

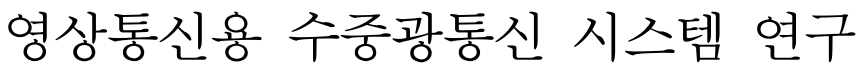

\author{
손현중* · 강진일 ${ }^{* *}$ Thieu Quang Minh Nhat · 김서강 ${ }^{*}$ 최형식@* \\ "한국해양대학교 기계에너지 시스템 공학과
}

**주)볼시스

KEY WORDS: Underwater optical wireless communication 수중 광 무선 통신, Underwater communication 수중통신

\begin{abstract}
In this study, we designed and developed an underwater LED communication system composed of an LED and a photo sensor. In addition, we experimented with video data transmission in a water tank. Two communication modules were installed in the $3 \mathrm{~m}$ water tank, and the image data transmission test was successfully performed at a rate of 20 frames per second(FPS), image resolution of $480 \times 272$, and data communication speed of 4 Mbps.
\end{abstract}

\section{1. 서 론}

최근 각국에서 해양에 대한 관심의 증가로 약 800 여종 이상 의 수중드론이 개발되어 해양탐사 및 자원개발에 사용되고 있 으며 이러한 수중드론의 증가와 함께 이들의 임무도 점차 다양 해지고 복잡해지고 있다. Side sonar scanner나 Multi-beam echo sounder 등을 장착하여 수중 지형을 매핑하여 해저 지형도를 만 들고, 이를 수중드론 간에 통신으로 전송하거나 수중에 설치된 통신노드로 전송하는 형태로 발전하여 수중에서 대량의 정보를 빠르게 보내는 통신기술이 점점 중요한 이슈가 되고 있다(Farr et al., 2005).

현재 음향파 통신은 수중통신에 폭넓게 응용되고 있지만 후 술할 다양한 문제점에 의해 수중에서 많은 용량의 데이터를 고 속으로 전송하기 어렵다. 이를 해결하기 위한 방안으로 미국 우 즈홀 해양연구소(Woods Hole Oceanographic Institution, WHOI), 메사추세츠 공과대학(Massachusetts Institute of Technology, MIT), 영국 소나다인사(Sonardyne International Ltd.) 등 수중로봇 최선 진국에서는 청색광 레이저 및 $\mathrm{LED}($ Light emitting diode)를 이용 한 수중 대용량 고속통신 연구가 활발히 이루어지고 있다.
본 논문에서는 음향파 수중통신과 가시광 수중통신 기술을 비교분석하고, 수중 광 무선통신에 대한 국내외 연구동향과 가 시광 수중통신의 활용분야를 소개하였다. 또한 소개한 수중 광 무선통신을 활용한 다양한 수중드론 운용 시스템 아이디어를 실현하기 위한 수단으로 수중에서 화상데이터와 같이 대량의 데이터를 빠른 속도로 전송할 수 있는 통신기술을 확보하고자 $\mathrm{LED}$ 와 광 검출센서로 구성된 수중 양방향 LED 통신 시스템을 연구 개발하였다. 그리고 개발한 통신 시스템을 수조에서 동화 상데이터 전송 시험을 성공적으로 수행하였다.

\section{2. 음향파 수중통신과 가시광 수중통신 비교 분석}

수중에서는 전자기파의 도달거리가 매우 짧아 수중통신은 많은 어려움이 있기 때문에 최근까지 수중에서의 통신은 모두 음향파를 사용하여 이루어졌다. 수중 음향파 통신은 수중에서 신호감쇠가 작아 가장 광범위하게 사용되고 있으나 다음과 같 은 문제점이 있으며, 수중 음향 링크의 다양한 범위에 대한 일 반적인 대역폭을 Table 1에 나타내었다(Kaushal and Kaddoum, 2016).

Received 2 March 2018, revised 10 April 2018, accepted 20 April 2018

Corresponding author Hyeung-Sik Choi; +82-10-5581-2971, hchoi@kmou.ac.kr ORCID: https://orcid.org/0000-0002-4060-8163 It is noted that this paper is revised edition based on proceedings of KMRTS 2017 in Seongnam. 
Table 1 Typical bandwidth for different ranges in underwater acoustic links

\begin{tabular}{llll}
\hline \hline Distance & Range $[\mathrm{km}]$ & Bandwidth $[\mathrm{kHz}]$ & Data Rate \\
\hline Very long & 1000 & $<1$ & $\sim 600 \mathrm{bps}$ \\
Long & $10-100$ & $2-5$ & $\sim 5 \mathrm{kbps}$ \\
Medium & $1-10$ & 10 & $\sim 10 \mathrm{kbps}$ \\
Short & $0.1-1$ & $20-50$ & $\sim 30 \mathrm{kbps}$ \\
Very short & $<0.1$ & $>100$ & $\sim 500 \mathrm{kbps}$ \\
\hline
\end{tabular}

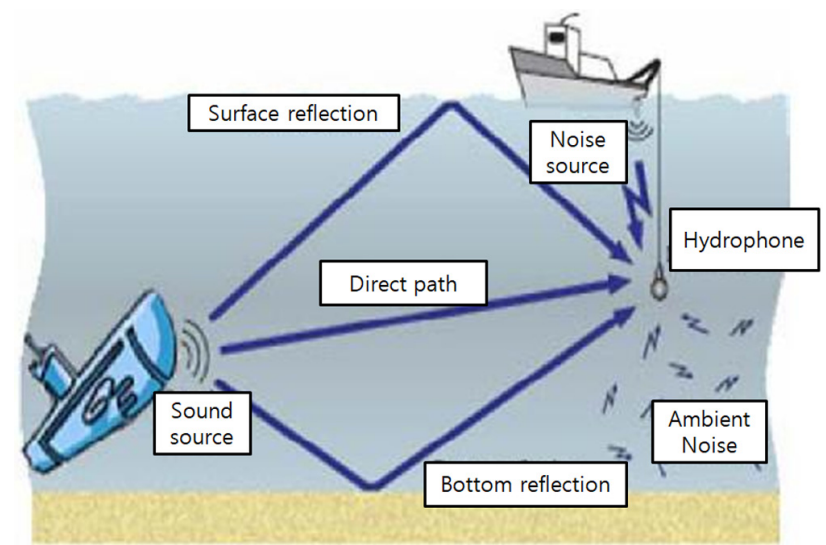

Fig. 1 Problems of Acoustic Communication

- 수중에서의 음파속도는 $1500 \mathrm{~m} / \mathrm{s}$ 전로 전자기파 속도에 비하 여 매우 느리다.

- 해수의 온도 변화와 분포 영향에 민감하다.

- 해수면에서 발생하는 선박 엔진소음, 스크루 소음 등의 잡 음에 취약하다.

- 음파의 반사와 굴절에 의한 다중경로 진행파의 간섭에 취약 하다.

- 데이터 전송속도가 $100 \mathrm{bps} \sim 100 \mathrm{Kbps}$ 이하로 제한되어 대용 량 데이터 전송에 많은 어려움이 있다.

- 데이터 전송효율 대비 높은 전력이 요구되기 때문에 배터리 자원이 한정된 수중드론 적용에 많은 제약이 있다.

- 음향파 통신모뎀 시스템 크기가 크기 때문에 용적이 제한된 수중드론에 적용하기에 많은 제약이 있다.
이러한 음향파 통신의 단점을 보완하기 위해 청색광을 이용 한 수중 고속통신 기술 개발에 대한 연구개발이 최근에 미국을 비롯한 선진 몇 개국에서 이루어지고 있다. 청색광은 수중 투과 가 가장 우수한 특징을 보이고 다음 장점이 있다.

- 청색광의 수중 전파속도는 광속이므로 데이터 고속전송이 가능하다.

- 해수의 온도 변화와 분포 영향에 무관하다.

- 해수면에서 발생하는 선박 엔진소음, 스크루 소음 등의 잡 음에 무관하다.

- 청색광의 수중 전파속도가 빠르기 때문에 반사와 굴절에 의 한 간섭이 없다.

Table 2는 음향파 수중통신과 가시광 수중통신 기술을 비교하 여 나타낸 것이다(Kaushal and Kaddoum, 2016).

\section{3. 가시광 수중통신 국내외 연구동향}

수중 광무선 통신 시스템의 국외 연구동향으로는 수중장비 최선진국인 미국에서 연구가 활발히 이루어지고 있으며 특히 우즈홀 해양연구소가 세계적으로 주목할만한 성과를 거두고 있 다. 국내외 연구동향을 살펴보면 다음과 같다.

\section{1 메사추세츠 공과대학(MIT)}

$\mathrm{MIT}$ 대학에서는 $5 \mathrm{~W}$ 청색 $\mathrm{LED}$ 6개와 $\mathrm{APD}$ 를 사용하여 $1.2 \mathrm{Mbps}$ 단방향 통신을 $30 \mathrm{~m}$ 거리까지 통신 가능한 수중 광무선 통신모뎀 을 개발하고 수중에서 케이블 없이 수중로봇을 제어하는 실험을 수행하였다(Doniec et al., 2010).

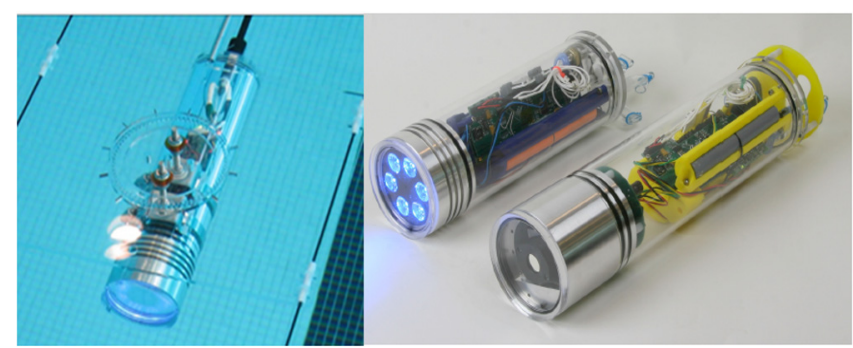

Fig. 2 Optical Communication Modem of MIT

Table 2 Acoustic Communication VS Optical Communication

\begin{tabular}{lll}
\hline \hline \multicolumn{1}{c}{ Parameter } & \multicolumn{1}{c}{ Acoustic } \\
\hline Attenuation & Distance and frequency dependent $(0.1-4 \mathrm{~dB} / \mathrm{km})$ & $0.39 \mathrm{~dB} / \mathrm{m}$ (ocean) $11 \mathrm{~dB} / \mathrm{m}$ (turbid) \\
Speed $[\mathrm{m} / \mathrm{s}]$ & $1500 \mathrm{~m} / \mathrm{s}$ & $\approx 225500000 \mathrm{~m} / \mathrm{s}$ \\
Data rate & $\sim \mathrm{kbps}$ & $\sim$ Gbps \\
Latency & High & Very Low \\
Distance & up to kms & $\approx 10 \sim 100 \mathrm{~meters}$ \\
Bandwidth & $1000 \mathrm{Km}<1 \mathrm{kHz}$ & $10 \sim 150 \mathrm{MHz}$ \\
Transmission power & $1 \sim 10 \mathrm{~km} \approx 10 \mathrm{kHz}$ & Few Watts \\
Efficiency & tens of Watts (typical value) & $\approx 30,000 \mathrm{bits} / \mathrm{Joules}$ \\
Performance parameters & $\approx 100$ bit/Joules & Absorption, scattering/turbidity, organic matter \\
\hline
\end{tabular}




\section{2 노스캐롤라이나 대학(Univ. of North Carolina)}

노스캐롤라이나 대학에서는 6각형 형태의 돔에 총 7 개의 포토 센서, $\mathrm{LED}$, 렌즈를 배치하여 광 검출 및 광 전송 시야각을 향상 시키고 상대방 광 통신 장치의 각도를 추정할 수 있는 수중 광 무선 통신 장치 연구 개발을 수행하였다(Simpson et al., 2012).
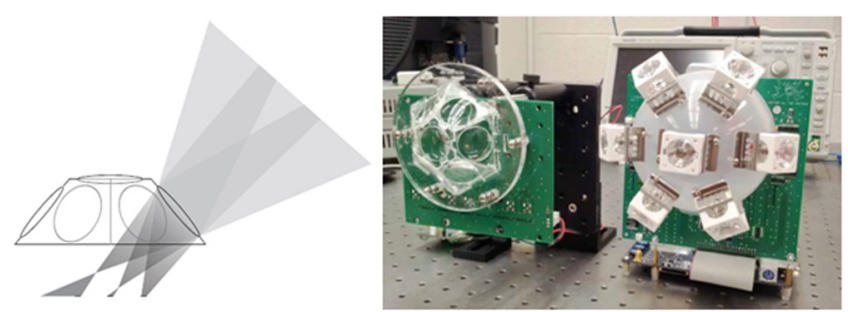

Fig. 3 Optical Communication Modem of N.C University

\section{3 우즈홀 해양연구소(Woods Hole Oceanographic Institution)}

우즈홀 해양연구소에서는 청색 LED 및 Laser와 광증배관 (Photomulti-plier tube, PMT)으로 구성된 수중 가시광 통신 시스템 을 오래 전부터 꾸준히 개발하였으며(Pontbriand et al., 2008) Table 3은 2015년 기준으로 도달한 성능을 나타낸 것이다(Pontbriand et al., 2015).

우즈홀 해양연구소는 개발한 가시광 수중통신 시스템을 실제 대양에서 다방면에 활용하고 있으며 대표적인 사례로는 북태평 양 해저에 수중 광통신 모뎀을 장착한 해저 관측노드(Fig. 4)를 설치하고 1 년 동안 수집된 해저 관측노드의 대용량 수집 데이

Table 3 WHOI underwater optical wireless communication spec (2015 year)

\begin{tabular}{cccc}
\hline \hline Rate & $\begin{array}{c}\text { Range } \\
{[\mathrm{m}]}\end{array}$ & Angle & $\begin{array}{c}\text { Technology } \\
{[\text { receiver / source }]}\end{array}$ \\
\hline $1 \mathrm{Mbps}$ & 138 & Hemisphere & PMT / LED \\
$10 \mathrm{Mbps}$ & 108 & Hemisphere & PMT / LED \\
$15 \mathrm{Mbps}$ & 80 & Hemisphere & PMT / LED \\
$>400 \mathrm{Mbps}$ & 4 & \pm 7 degrees & PMT / Laser \\
$10 \mathrm{Gbps}$ & Contact & \pm 2 degrees & Photodiode / Laser \\
\hline
\end{tabular}

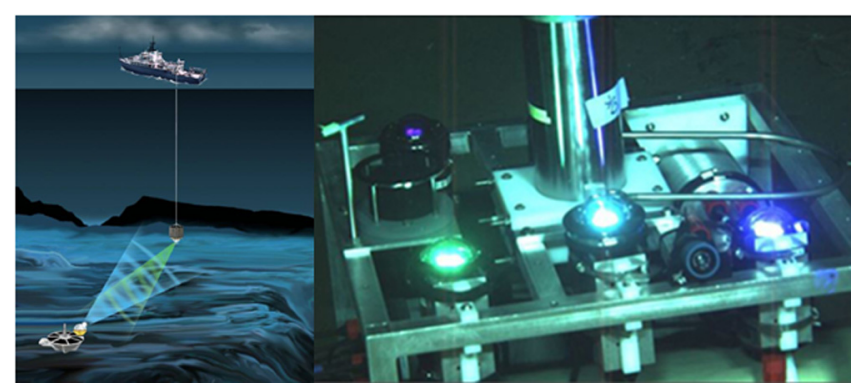

Fig. 4 Underwater optical communication observation node of WHOI

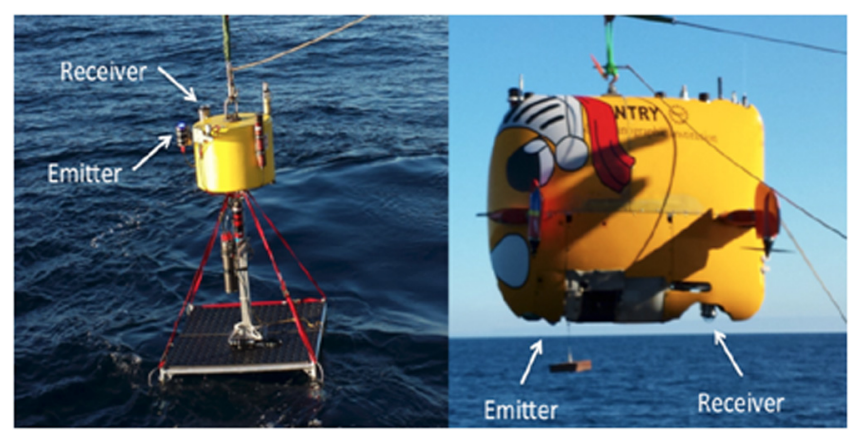

Fig. 5 Underwater optical communication network of WHOI

터를 광통신으로 회수에 성공함으로 해저 관측노드를 인양하는 비용과 시간을 절약한 사례가 있다(Farr et al., 2013).

또한 가시광통신 모뎀을 장착한 해저 노드(Fig. 5)로 수중 광 역통신망을 구축하여 수중에서 임무중인 AUV(Autonomous underwater vehicle)와 실시간 고속통신 네트워크를 구축하여 많 은 데이터를 고속으로 취득하거나 실시간으로 $\mathrm{AUV}$ 제어 등의 기술을 개발하고 있다(Pontbriand et al., 2015).

\section{4 영국 소나다인 사(Sonardyne International LTD)}

음향파 통신장비 분야의 유명 업체인 영국 Sonardyne 사는 미 국 우즈홀 해양연구소, MIT와 기술협약을 통해 수중 광 무선통 신 모뎀을 세계에서 최초로 상용화, 상업적으로 가치가 있음을 증명한 사례가 있다. 다음의 Table 4는 Sonardyne 사의 수중 광 무선통신 모뎀 상용제품을 정리한 것이다.

Table 4 UK Sonardyne's underwater wireless communication module products

\begin{tabular}{|c|c|c|}
\hline $\mathrm{N}_{\text {Specification }}^{\text {Model }}$ & BlueComm 100 & $\begin{array}{c}\text { BlueComm } 200 \\
\text { (Operates only in deep water } \\
\text { environments greater than } 1000 \text { meters) }\end{array}$ \\
\hline Light source & Blue LED Array & Blue LED Array \\
\hline Bit rate & $1 \sim 5 \mathrm{Mbps}$ & $1 \sim 12.5 \mathrm{Mbps}$ \\
\hline Communication range & up to $10 \mathrm{M}$ & up to $150 \mathrm{M}$ \\
\hline Communications Interface & Ethernet & Ethernet \\
\hline Photo & & \\
\hline
\end{tabular}




\section{5 국내 연구동향}

국내 연구동향으로는 한국해양대학교에서 수중 광 무선통신 기 반기술을 확보하고자 관련 연구를 2013년도부터 꾸준히 진행하여 현재 천해에서 최대 통신속도 $5 \mathrm{Mbps}$, 최대 통신거리 $20 \mathrm{~m}$ 수준에 도달하였으며 이는 영국 Sonardyne 사에서 상용화 중인 천해용 수 중 광 통신 모뎀(BlueComm 100)의 사양이 천해에서 최대 통신속도 $5 \mathrm{Mbps}$, 최대 통신거리 $10 \mathrm{~m}$ 인 점을 비교하면 통신속도는 동일하고 최대 통신거리가 $10 \mathrm{~m}$ 더 우수한 수준의 성능이다. Fig. 6은 한국해 양대학교에서 개발해온 광 무선 통신 장치를 함께 나타낸 것이다. 그리고 Fig. 7은 한국해양대학교의 기술을 이전 받아 (주BORsys에 서 제작한 BOLcomm 100 (천해 $100 \mathrm{~m}$ 용)의 사진이다.
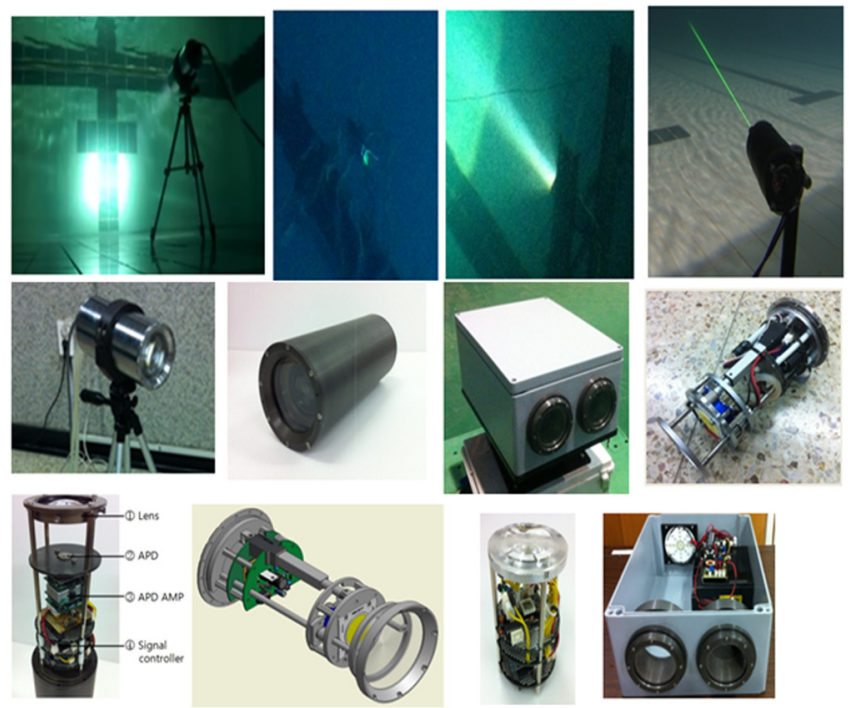

Fig. 6 Optical Communication Modems of Korea Maritime University
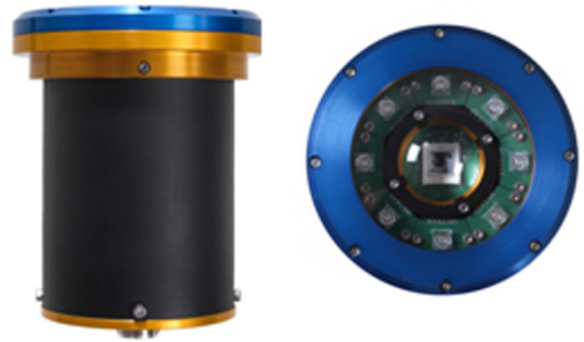

Fig. 7 Underwater Optical Communication Modem of BORsys Co Ltd. (BOLcomm100)

\section{4. 가시광 수중통신 활용분야}

가시광 수중통신 기술을 효과적으로 활용할 수 있는 분야로는 수중로봇 원격 고속통신, 다이버 통신, 해양방위, 광역 수중통신 네트워크 등을 들 수 있다. 또한 가시광 수중통신 기술은 이 장에서 소개한 분야에 국한되지 않고 이외에 다양한 활용분야가 존재한다.

\section{1 수중로봇 원격 고속통신 분야}

화상이나 데이터를 실시간으로 모니터링하거나 실시간 제어 가 필요한 수중로봇 운용 시 유선 케이블을 사용하는 것이 일
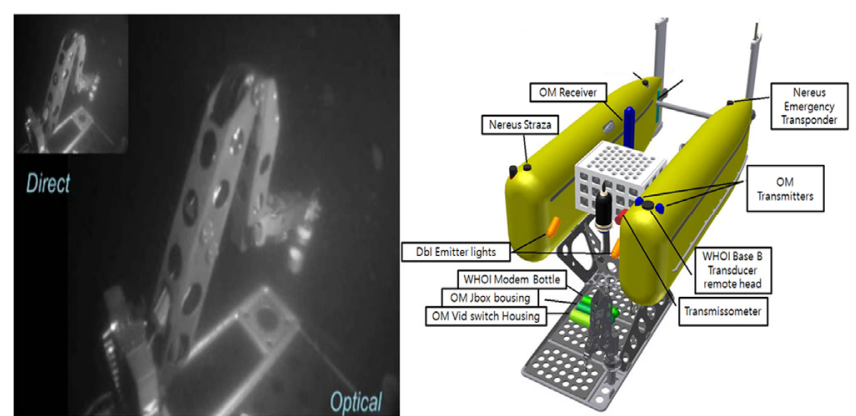

Fig. 8 WHOI's Un-Tether ROV

반적이나 유선 케이블 통신의 경우 케이블 길이가 길어질수록 수중 운동체의 동작에 많은 저항력을 미치고 조류가 있는 환경 에서 적용이 어려운 문제가 있다. 이러한 문제점을 해결하기 위 해 고속통신이 가능한 가시광 수중통신 기술을 적용하여 케이 블이 없는 실시간 제어 수중로봇을 개발하려는 연구가 수행되 고 있다. 다음 Fig. 8은 미국 우즈홀 해양연구소에서 가시광 통 신 기술을 적용하여 개발 및 시범 운용중인 Un-Tether ROV (Remotely operated vehicle)이다(Bowen et al., 2013).

$\mathrm{AUV}$ 의 운용을 위해서는 진수 및 회수 작업을 위해 운용 인 력이 탑승한 모선이 수반되어야 하며 임무 종료 후 취득 데이 터를 얻기 위해서는 반드시 수중로봇을 인양 하여야만 하는 문 제점이 있다. 이러한 문제점을 해결하기 위해 가시광 수중통신 을 적용한다면 수중로봇을 인양하지 않고도 취득 데이터를 내 려받거나 운용 프로그램 입력 등의 필요한 작업이 가능해지게 되며 특히 운용 인력과 모선이 불필요해지므로 수중로봇 운용 비용을 크게 절감할 수 있다. 또한 무선 수상선(Unmand surface vehicle, USV) 또는 수중 노드를 활용한다면 지역에 제한을 받 지 않고 더욱 효과적인 운용이 가능할 것이다.

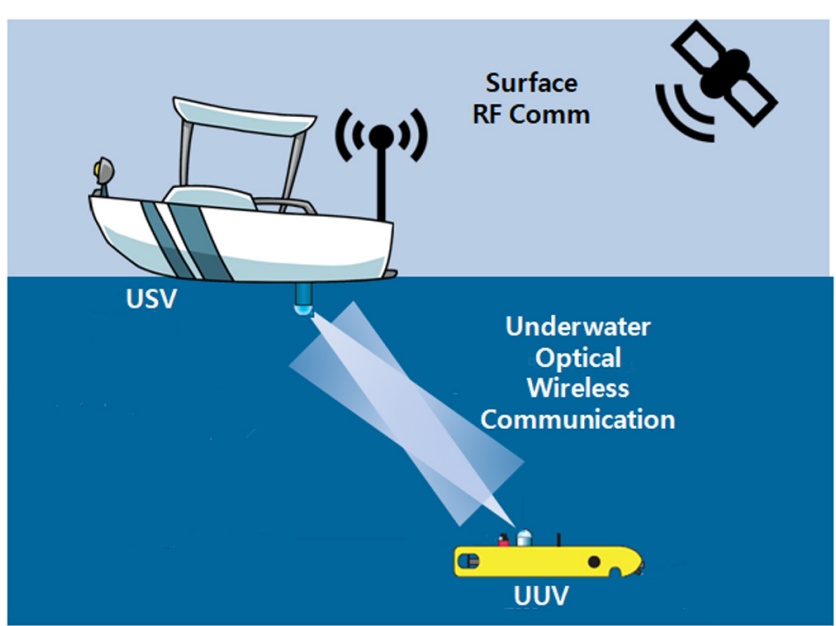

Fig. 9 USV and AUV optical underwater communication concept design

\section{2 다이버 통신 분야}

레저활동나 수중작업 등 다이버들의 수중 활동 증가로 이들 에 대한 안전과 원활한 작업수행을 위하여 다이버와 통신이 필 연적으로 늘어나면서 다양한 수중 통신장비들이 개발되고 있는 
추세이다. 현재는 수중 다이버간의 의사소통은 미리 약속된 수 신호를 활용하거나, 음향파를 이용한 전통적인 통신수단 밖에 존재하지 않기 때문에 양질의 음성, 영상이미지 등의 대용량 데 이터를 전송하기 어렵고, 작업선이나 육상으로 전달할 수 있는 무선 통신 수단이 없는 실정이다.

이에 대응하여 수중 가시광 통신을 활용한다면 수중에서 다 이버-다이버간 의사소통 뿐만 아니라 수중 촬영 영상등을 선상 이나 육상으로 실시간 전송하여 해상 크레인과 같은 중장비와 연계한 작업수행에도 활용할 수 있을 것이다. 또한 다이버들의 안전사고를 방지하기 위하여 작업선에서도 다이버의 상태를 확 인할 수 있는 안전장치로도 활용 가능할 것이다. Fig. 10은 일본 다이요 요덴사와 Nakagawa Labs Inc.에서 개발 중인 수중 다이 버 가시광 통신장치이다.

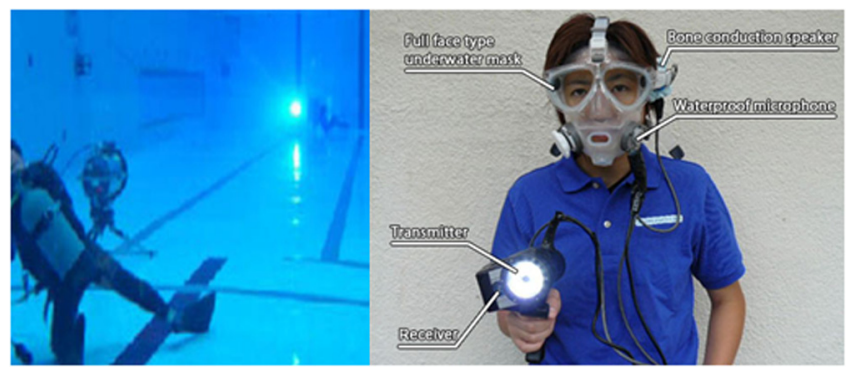

Fig. 10 Japanese company's diver underwater optical communication device

\section{3 해양방위산업 분야}

기동중인 군사용 잠수함과의 통신을 위하여 기존에는 RF(Radio Frequency)통신이나 수중음향통신 기법이 적용되었으나 이는 적에 게 노출되기 쉬워 가로채기(Interception)나 재밍(Jamming) 기회를 제공하게 될 수도 있다. 이를 극복하기 위한 방법으로 고지향성을 가지면서 해수 투과율이 높은 청록 레이저를 이용한 방위산업 목 적의 가시광 수중통신이 연구되고 있다. 가시광 수중통신을 활용 할 경우, 소스신호 가로채기나 재밍 등의 해킹시도가 매우 어려울 뿐만 아니라 많은 데이터를 고속으로 짧은 시간에 상호교환이 가 능하므로 통신 노출시간을 다른 통신수단에 비하여 크게 단축시킬 수 있는 점은 저피탐(Low probability of interception, LPI)을 달성하 기 쉽게 되므로 결과적으로 기동중인 잠수함이 노출될 확률이 감

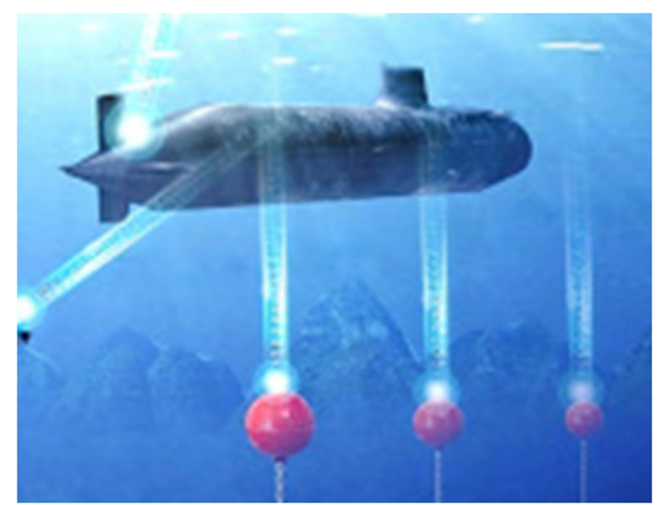

Fig. 11 Underwater optical communication application of military submarine and UUV
소하는 효과가 있다.

또한 공격형 잠수함 탑재 무인잠수정(Unmanned underwater vehicle, UUV)의 다양한 군사적 활용도가 증가하고 있어 여기에 수중 가시광 통신기술을 적용한다면 UUV의 정밀 사출 및 도킹, 실시간 화상데이터 및 대용량 수집데이터를 짧은 시간 내에 전 송 등을 실현할 수 있어 UUV의 보다 효과적인 군사적 응용이 가능해질 것이다.

\section{4 광역 수중통신 네트워크망 분야}

광역 수중통신 네트워크는 넓은 범위의 수중에 걸쳐서 각종 수중 정보를 수집하고 이를 수중 기지국을 통해 지상으로 전송 하는 형태로, 수중 센서를 통해 수집된 정보가 해양 기후 관측 및 생태 환경 분석 등의 분야와 선박의 항로 정보 등 해운산업 분야, 영해 방위를 위한 국방 분야 등 다양한 영역에서 활용이 가능하다. 또한, 수중에서의 탐지 기능을 통해 해수의 온도와 흐름뿐만 아니라 해저 지진파 등의 감지를 통해 해양 기후의 관측과 해저에서 시작되는 자연 재해에 대해 보다 정확한 예측 을 하는 것은 물론 선박 사고 등에 대해서도 신속한 대처가 가 능하기 때문에 우리나라를 포함한 각국에서 광역 수중통신 네 트워크에 관심과 투자개발이 활발하게 진행되고 있다.

주목할 만한 사례로는 유럽연합의 유-무선 방식을 혼용한 '썬라이즈 프로젝트'와 캐나다 비영리단체 오션 네트웍스에서 운용하고 있는 유선망 기반 센서 수집 및 수집데이터 실시간 원격 관측시스템이 있다. 특히 해양의 물리적, 화학적, 생물학 적, 지질학적 수중 데이터가 200기가바이트 이상이 매일 수집되 고 있다. 이 방대한 데이터를 전송 및 처리하기 할 수 있는 통 신수단은 수중 가시광 통신 기술이 매우 유력하다. 수중광 통신 노드는 통신거리가 짧은 단점이 있지만 광섬유로 이들을 길게 연결하면 초고속 광역 통신망이 구성될 것이다. 이러한 시스템 을 구성하면 수중 광통신 관련 제품들의 시장이 크게 확장될 것으로 사료된다. Fig. 12는 Salish Sea 수역에 구축된 광역 수중 통신 네트워크 시스템을 나타낸 것이다.

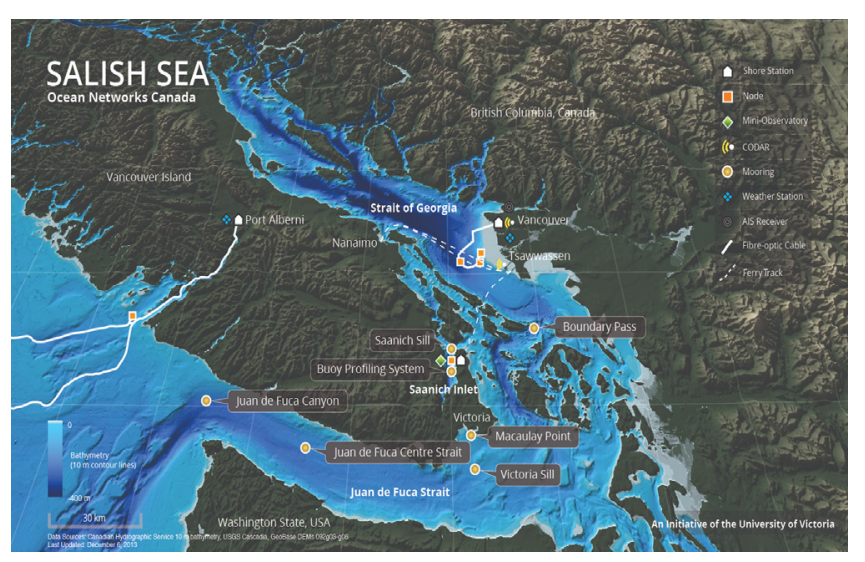

Fig. 12 Wide-area underwater communication network system built in Salish Sea

\section{5. 수중 광 통신 시스템 설계}

앞에서 서술한 국외 연구동향과 같이 수중드론의 개발 및 활 
용이 증가하면서 함께 이들의 임무도 점차 다양해지고 있다. 그 리고 이를 보다 저비용, 효율적으로 운용하기 위해 다양한 운용 시스템에 대한 아이디어가 제안되고 있다. 이 아이디어를 실현 하기 위한 핵심수단으로 수중에서 대량의 정보를 빠르게 전송 하는 통신기술이 점점 중요한 이슈가 되고 있다.

본 논문에서는 이러한 동향에 발맞춰 수중에서 동화상데이터 와 같은 대량의 데이터를 짧은시간에 전송할 수 있는 통신기술 을 확보하고자 $\mathrm{LED}$ 와 광 검출센서로 구성된 수중 양방향 $\mathrm{LED}$ 통신 시스템을 설계, 제작하였다.

\section{1 송신-수신 일체형 수중 광 통신모뎀 설계 및 제작}

단일 실린더 통신모뎀으로 수중 양방향 광 통신을 구현하기 위해 송신파트와 수신파트가 통합된 형태로 하드웨어 구조를 설계하였다. 송신파트는 전송하고자 하는 데이터를 LED 광 에 너지로 변환해 전송하기 위한 것으로 크게 광학장치, LED, LED 드라이버, 컨트롤러로 구성되어 있으며 수신파트는 LED 송신기 에서 방출된 광을 검출하고 적절한 신호처리를 통해 원래의 데 이터를 복원하는 장치로 크게 집광장치, 포토센서, 전단증폭기, 2차 증폭기 및 신호처리기로 구성되어 있다. 이를 구체적으로 살펴보면 다음과 같다.

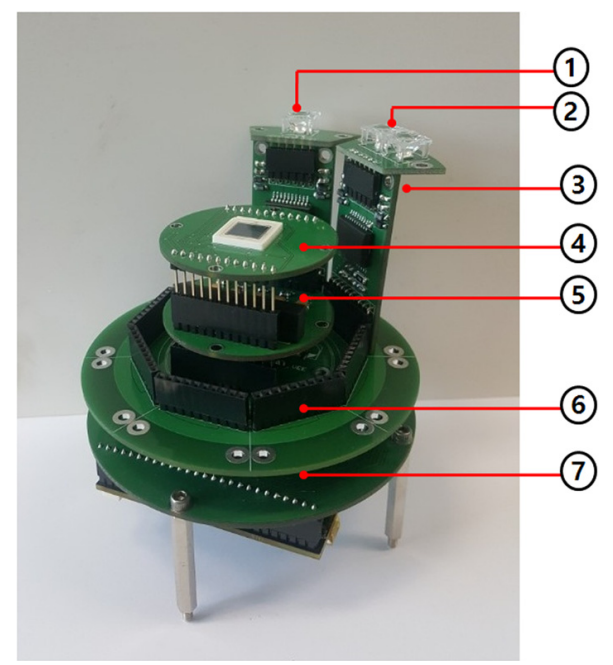

Fig. 13 Integrated optical modem $\mathrm{H} / \mathrm{W}$ structure

(1) : LED 광의 직진성을 향상시킬 수 있는 콜리메이트 렌즈 등의 광학 장치로 구성하였다.

(2) : 수중에서 투과율이 좋은 $450 \mathrm{~nm}$ 청색파장의 $\mathrm{LED}$ 로서 고 출력이면서도 고속 응답이 가능한 Low Capacitance LED 를 선정하였다.

(3) : 전송하고자 하는 데이터를 LED 구동 전류로 변환하며 특히 매우 빠른 속도로 LED를 On-off를 하여야 하므로 고속의 LED 드라이버를 구성하였다.

(4) : 광수신기는 고이득 포토다이오드를 사용하여 저에너지 광 신호를 효과적으로 검출하고 주변 광 잡음을 필터링 하고 통신 데이터를 디코딩 할 수 있도록 구성하였다.

(5) : 포토다이오드의 출력 전류를 입력으로 받아 비례전압을 출력하는 전단 증폭기 및 전단증폭기로부터 얻어진 신 호에 노이즈 제거, 구형파 복원등의 신호처리 과정을 거
쳐 원신호 복원을 하는 신호처리 시스템을 단일 기판에 집적하였다.

(6) : 전단증폭기 게인, 노이즈 차단주파수 설정, 구형파 복원 기준점 등의 광 수신에 관련된 파라미터를 원격으로 제 어할 수 있도록 구성하였으며 자율 알고리즘에 의해 최 적화된 광 수신 파라미터를 스스로 조정하도록 프로그 램하였다.

(7) : RS422, RS485, Ethernet의 통신 인터페이스를 지원하기 위한 보드로 통신모뎀 제어를 위한 별도의 통신처리 회 선을 포함하도록 구성하였다.

개발한 광 통신모뎀의 설계목표 사양을 Table 5 에 나타내었다.

Table 5 Optical modem design specification

\begin{tabular}{ll}
\hline \hline Light source & $450 \mathrm{~nm}$ BLUE LED Array \\
Optical Power & 6 Watts (Radiated light) \\
Optical Beam & $7^{\circ}$ Half angle emitter beam \\
Sensor & PIN, APD \\
Comm Range & 20 metres maximum \\
Bit Rate & $0.1 \sim 5$ Mbps \\
Comm Interface & RS422, RS485, Ethernet \\
\hline
\end{tabular}

\section{2 제작한 광 통신모뎀 통신성능 검증}

제작한 광 통신모뎀의 수중통신 성능을 평가하기 위해 가로 $3 \mathrm{M}$ 크기의 실험수조에서 수중통신 실험을 수행하였다(Fig. 14). 송수신부 거리를 실험수조의 최대 길이인 $3 \mathrm{~m}$ 로 고정하고 안정 적으로 통신 가능한 최대 통신속도를 측정하였다. 측정 방법으 로는 전송 데이터 $0 \mathrm{x} 00-0 \mathrm{xFF}$ 중에서 $0 \mathrm{xAA}(0 \mathrm{~b} 01010101)$ 또는

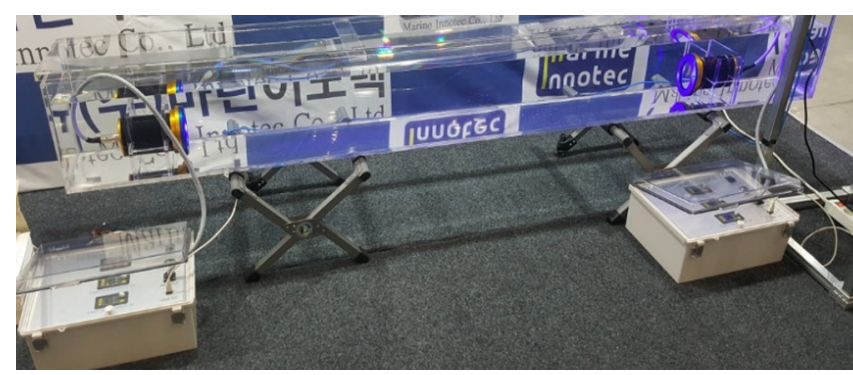

Fig. 14 LED underwater communication performance test

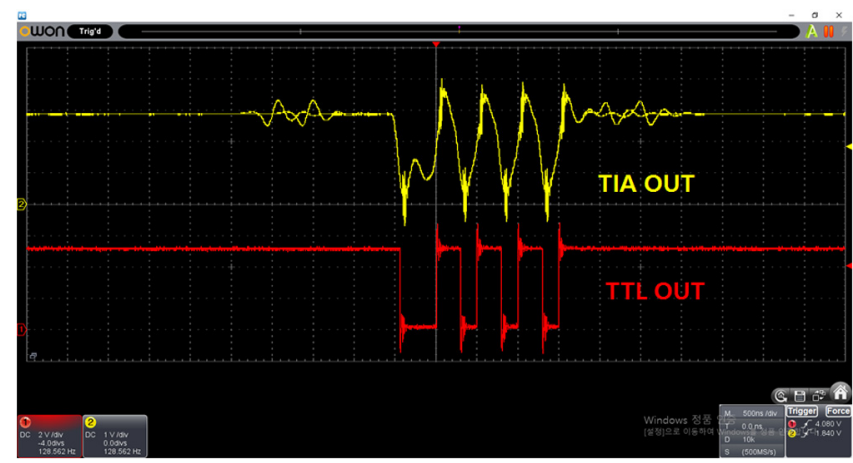

Fig. 15 Receive waveform of 0xAA data 
0x55(0b10101010)가 비트변화율이 가장 높은 점(Fig. 15)을 이용 하여 $0 \mathrm{xAA}$ 의 $1 \mathrm{Byte}$ 데이터를 연속적으로 송신 및 수신하여 값 이 일치하는지 검사하는 소프트웨어를 작성하여 반복시험을 10 만 번 이상 수행하는 방법으로 통신성능을 측정하였다.

그 결과, 최대 $4 \mathrm{Mbps}$ 까지, 10 만 번 테스트 중 13 개 에러 발생 율로 안정적인 수중통신이 가능함을 확인하였다.

본 논문에서 개발한 통신모뎀은 최대 $5 \mathrm{Mbps}$ 까지 통신가능하 도록 설계하였으나, 사용한 PC to RS485 통신 인터페이스 장비 가 최대 $4 \mathrm{Mbps}$ 까지 지원되는 문제점이 있어 본 실험에서는 최 대 $4 \mathrm{Mbps}$ 까지 실험을 수행하였다.

\section{6. 수중 광 통신을 이용한 수중동영상 통신 시스템 설계 및 제작}

\section{1 수중 광 통신용 영상 통신 소프트웨어 설계}

USB CAM(Universal serial bus camera)에서 촬영한 이미지 데 이터를 수중 광통신을 통해 전송하는 영상 전송 소프트웨어의 개념설계도를 Fig. 16과 같이 나타내었다. 카메라 호환성을 높 이기 위해 USB CAM 종류의 카메라를 호환할 수 있으며 사용 자가 지정한 해상도로 이미지 캡쳐를 해서 얻은 비트맵 이미지 데이터를 JPEG로 압축하여 이미지 용량을 줄인다. 압축된 JPEG 이미지를 Byte 배열로 변환한 후 STX(Start of text), 전체데이터 길이, $\mathrm{ETX(End} \mathrm{of} \mathrm{text)} \mathrm{등의} \mathrm{필요한} \mathrm{정보를} \mathrm{추가하여} \mathrm{프로토콜}$ 패킷 매칭을 한 후 광 통신 모뎀의 송신측에 전송한다.

$\mathrm{LED}$ 송신기와 광수신기가 한 쌍으로 구성된 통신모듈을 수 면과 수중에 각각 설치한다. 그리고 이 통신모듈들은 서로 광

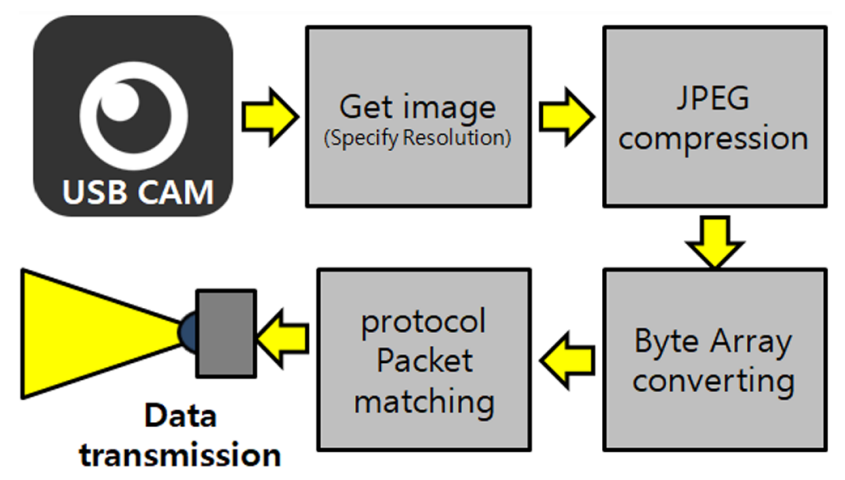

Fig. 16 Schematic of underwater video data transmission

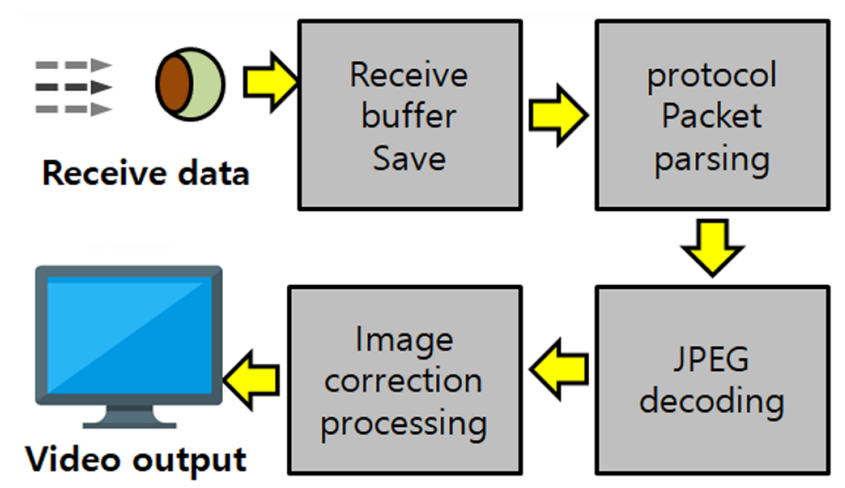

Fig. 17 Schematic of receiving underwater video data
통신 모뎀에서 수신된 이미지 데이터를 파싱, 디코딩하여 영상 출력하는 영상 수신 소프트웨어의 개념설계도를 Fig. 17과 같이 나타내었다. 광 통신 모뎀에서 수신된 데이터는 상시 수신버퍼 에 저장되며 소프트웨어의 쓰레드 프로그램은 수신 버퍼에 저 장된 데이터를 파싱하여 STX, 이미지 데이터길이, ETX를 분리 한다. 분리된 이미지 데이터는 JPEG 디코딩을 통해 이미지를 복원하며 복원된 이미지에 이미지 확대 축소 등과 같은 필요한 이미지 보정 작업을 한 후 최종적으로 사용자의 모니터에 이미 지를 출력한다.

위 Fig. 16와 Fig. 17의 이미지 송신-수신 절차 한번에 1프레임 의 영상 전송이 이루어지며 보레이트, 소프트웨어 처리시간 등 에 따라 초당 전송, 수신 가능한 최대 프레임 수가 결정된다.

\section{2 수중 광 통신용 영상 통신 시험 및 결과}

5.2절에서 기술한 바와 같이 구성된 실험수조 환경에서 수중 광 통신모뎀을 설치하고 영상 통신 시험을 수행하였다(Fig. 18). 영상 전송 시험 결과를 Table 6에 나타내었다.

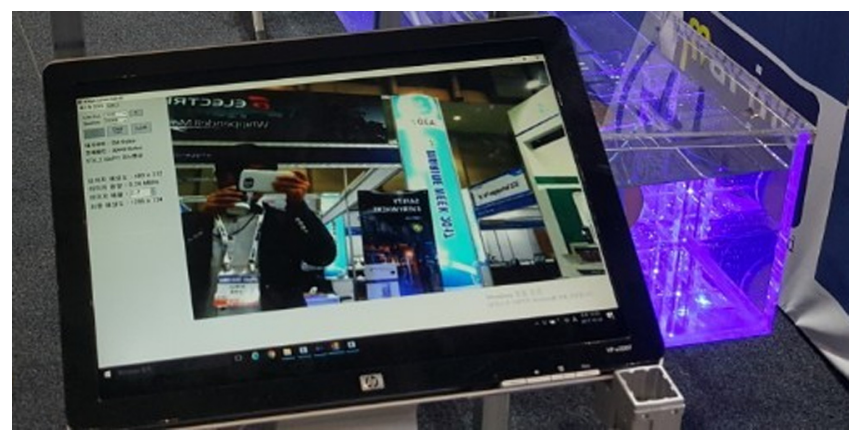

Fig. 18 Video transmission / reception software UI \& Video communication experiment environment

Table 6 Video transmission test result

\begin{tabular}{ll}
\hline \hline Bit Rate & 4 Mbps \\
Image Resolution & $480 \times 272$ \\
Image Data Size & Average 0.2 Mbit \\
Received image frame & $20 \mathrm{FPS}$ \\
Error rate & no error in 10 hour continuous test \\
\hline
\end{tabular}

광 통신모뎀의 보레이트는 $4 \mathrm{Mbps}$ 로 하였으며 $480 \times 272$ 해상 도의 이미지 데이터를 전송하고자 했을 때 평균 이미지 데이터 의 크기는 $0.2 \mathrm{Mbit}$ 전후로 측정이 되었다. 실제로 영상전송을 했을때 20FPS 정도의 프레임이 측정되었으며 광 통신모뎀의 광 을 차단하지 않는 이상 이미지 수신의 에러가 발견되지 않았다.

\section{7. 결 론}

수중드론의 개발 및 활용이 증가하면서 함께 이들의 임무도 점차 다양해지고 있다. 그리고 이를 보다 저비용, 효율적으로 운용하기 위해 다양한 운용 시스템에 대한 아이디어가 제안되 고 있다. 이 아이디어를 실현하기 위한 핵심수단으로 수중에서 대량의 정보를 빠르게 전송하는 통신기술이 점점 중요한 이슈 
가 되고 있지만 음향파 통신은 수중에서 장거리 전파가 가능하 지만 낮은 대역폭 문제점에 의해 수중에서 많은 용량의 데이터 를 고속으로 전송하기 어렵기 때문에 이런 문제점을 해결할 필 요가 있다.

본 논문에서는 음향파 수중통신과 가시광 수중통신 기술을 비교분석하고, 수중 광 무선통신에 대한 국내외 연구동향과 가 시광 수중통신의 활용분야를 소개하였다. 또한 소개한 수중 광 무선통신을 활용한 다양한 수중드론 운용 시스템 아이디어를 실현하기 위한 수단으로 수중에서 화상데이터와 같이 대량의 데이터를 빠른 속도로 전송할 수 있는 통신기술을 확보하고자 $\mathrm{LED}$ 와 광 검출센서로 구성된 수중 양방향 $\mathrm{LED}$ 통신 시스템을 연구 개발하였다. 그리고 개발한 통신 시스템을 길이 3 미터 수 조에서 $4 \mathrm{Mbps}$ 통신 속도로 $480 \times 272$ 해상도의 이미지를 초당 20 프레임의 속도로 수조에서 동화상데이터 전송 실험을 성공적으 로 수행하였다.

본 논문에서 개발한 양방향 LED 통신 시스템은 수중에서 대 량의 데이터 고속전송이 필요한 다양한 수중드론에 적용할 수 있을 것으로 기대되며 향후 수중 광 통신모뎀의 활용범위를 높 이기 위해 멀티빔 소나 등의 대용량 계측 데이터 무선 통신실 험 등을 실해역에서 수행할 예정이다.

\section{후 기}

본 연구는 민군협력진흥원이 지원하는 2017년도 민군겸용기 술개발사업인 다중센서를 이용한 무인잠수정의 종단 유도 및 도킹 기술 개발 과제로 수행된 연구결과임.

\section{References}

Bowen, A.D., Jakuba, M.V., Farr, N.E., Ware, J., Taylor, C., Gomez-Ibanez, D., Machado, C.R., Pontbriand, C., 2013. An Un-tethered ROV for Routine Access and Intervention in the Deep Sea. In Oceans-San Diego 2013, IEEE., 1-7.

Doniec, M., Detweiler, C., Vasilescu, I., Rus, D., 2010. Using Optical Communication for Remote Underwater Robot Operation. In Intelligent Robots and Systems (IROS), 2010 IEEE/RSJ International Conference on, IEEE, 4017-4022.

Farr, N., Chave, A., Freitag, L., Preisig, J., White, S., Yoerger, D., Titterton, P., 2005. Optical Modem Technology for Seafloor Observatories. In OCEANS 2005, Proceedings of MTS/IEEE, 928-934.

Farr, N.E., Ware, J.D., Pontbriand, C.T., Tivey, M.A., 2013. Demonstration of Wireless Data Harvesting from a Subsea Node using a "Ship of Opportunity". In Oceans-San Diego 2013, IEEE, 1-5.

Kaushal, H., Kaddoum, G., 2016. Underwater Optical Wireless Communication. IEEE Access, 4, 1518-1547.

Pontbriand, C., Farr, N., Ware, J., Preisig, J., Popenoe, H., 2008. Diffuse High-bandwidth Optical Communications. In OCEANS 2008, IEEE, 1-4.

Pontbriand, C., Farr, N., Hansen, J., Kinsey, J.C., Pelletier, L.P., Ware, J., Fourie, D., 2015. Wireless Data Harvesting using the AUV Sentry and WHOI Optical Modem. In OCEANS'15 MTS/IEEE Washington, IEEE, 1-4.

Simpson, J.A., Hughes, B. L., Muth, J.F., 2012. Smart Transmitters and Receivers for Underwater Free-space Optical Communication. IEEE Journal on Selected Areas in Communications, 30(5), 964-974. 